\title{
EXPLORING THE PERCEPTION OF SELF ESTEEM AMONG HIGH SCHOOL ATHLETES
}

\author{
Dilsad Ahmed ${ }^{1}$, Marijana Mladenovic ${ }^{2}$, Walter King Yan $\mathrm{Ho}^{1}$, \\ $\mathrm{Ki}-\mathrm{Cheon} \mathrm{Lee}{ }^{3}$, and Babar Ali Khan ${ }^{4}$ \\ ${ }^{1}$ University of Macau, Taipa, Macau, China \\ ${ }^{2}$ University Singidunum Belgrade, Serbia \\ ${ }^{3}$ Korea University, Seoul, South Korea \\ ${ }^{4}$ DCPE, SGB Amravati University, Amravati, Maharashtra, India
}

\section{SUMMARY}

The main purpose of this study was to explore the self esteem among high school athletes with regard to their participation in recreational and leisure activities and also to see the differences of self esteem level between both sexes (male and female). To achieve the study purpose, 250 (124 male and 126 female) adolescent athletes at the high school level were invited to participate in this survey. Their ages were ranged from 12 to 17 years. They were invited on the basis of their active participation in games and sports and also those who used to participate in various tournaments conducted by the District Sports Office, under the authority of Directorate of Sports, Assam. They were asked to indicate their perception of self esteem on their games and sports participation. The Principal Component analysis extraction and Varimax Rotation methods were adopted for analysis the 10 items in this survey. Three items showed low factor loading $(<.50)$ after EFA. Description of the three items is "I feel that I have a number of good qualities"; "I feel that I'm a person of worth, at least on an equal plane with others", and "On the whole, I am satisfied with myself". Level of self esteem between male and female was found significantly different as it was hypothesized earlier. The results were further enhanced with Confirmatory factor analysis where the result of the Confirmatory factor analysis Model Fit Summary indicated: $\chi^{2}=36.928$ with $d f=32$ to be significant as CFI $=.978$, RMSEA $=.025$, GFI $=.972$, $\mathrm{AGFI}=.952$, PGFI $=.566, \mathrm{PCLOSE}=.905$.

Key Words: adolescent, exploratory and confirmatory factor analysis, recreational and leisure activities, self esteem.

\section{INTRODUCTION}

Self esteem is sometimes indicated as an intricate model (Marsh, 1986, 1995; Marsh, Hey, Roche, \& Perry, 1997) for researchers to study as its complex, hierarchical and multidimensional nature attracts our attention (Steinberg, 1996). Self esteem associated with the self worth of an individual through by which someone assesses the overall performance and positive self worth. Self esteem is an important aspect of an individual's own identity. Self esteem is defined by the degree of worth and competence that we attribute to ourselves. It has an important role in achieving good results, if you deeply believe in your own skills and abilities, you will perform well. If there is no such faith but doubts which prevails, the sportsman will have the feeling that the task is far too hard for him, beyond his potentials (Hardy \& Crace, 2009, Velikić, Knežević, \& Rodić, 2014). Through sport, we may enhance our self esteem by having a positive image of our bodies and the physical skills and abilities that we develop. A number of research proved that participation in games and sports and exercise (Vealey, 1992) is usually positively enhances the level of self esteem exercise, but at the same time it is also found that this level is the most stable and difficult to change 
(Marsh, 1986, 1995; Marsh, Hey, Roche, \& Perry, 1997). Adolescent age is the crucial period to develop self worth and self assessment and overall assessment of how one feels about oneself. Understanding how individuals feel about themselves has been a quest of researchers for many years (Blumer, 1969; Mead, 1934). It has been seen that the development of self esteem is an important need to develop among the adolescent because it is the period when they discover the things around them and assume different perception out of it. So it is found from research findings that we feel a kind of positive self worth through the recognition received from family and friends and the social relationships (Holland \& Andre, 1994). The self esteem development as a result of our involvement in sport and physical activity is being enhanced. Yet, we may be vulnerable to low self esteem in sport and physical activity if we perceive our body to be inadequate, unfit or inappropriate for our selected activity. We may feel that our self-worth is judged on our losses and wins versus our abilities and intentions. The intensive participation in sport may lead to social isolation and lack of family support. All of these negative emotions need to be refocused in order to build positive self-esteem. Coaches, physical education teachers and active living leaders can positively influence self-esteem and provide girls and women with ongoing incentive to participate and personally succeed in physical activity endeavours. Thus, the self esteem is an aspect that needs to be enhanced and the participation in games and sports across both sexes should be an agenda in the study. As, it is evident from the number of research that participation in games and sports and exercise (Vealey, 1992) positively enhances the level of self esteem. This association holds for many kinds of athletic activity, such as playing a sport, taking a Taekwondo class (Bosscher, 1993), weight training (Finkenberg, 1990; Ford, Puckett, Reeve, \& Lafavi, 1991; Melnick \& Mookerjee, 1991; Pascarella \& Smart, 1991), or running, and for various populations, particularly male and female children, adolescents (Delaney \& Lee, 1995; Kalliopuska, 1987), and adults (Vealey, 1992; Wilkins, Boland, \& Albinson, 1988; Yeung \& Hemsley, 1996). Again in another study it was found that there is relationship conducted by between exercise activity and self-esteem was positive for men, but no concordance for women and even negative for young women under 21 (Tiggemann \& Williamson, 2000). In view of these somewhat conflicting findings, the main purpose of the study was decided to explore the self esteem among the athletes with regard to their participation in recreational and leisure activities and also to see the level of self esteem differences between both sexes (male and female). It was hypothesized that all the items on Self Esteem would be retained after exploratory factor analysis. It was also hypothesized that male athletes would have a higher level of self esteem in comparison to the female high school level athletes because of various socialization reasons as well as parents unequal eye on female physical activity participation. It was further hypothesized that the CFA adjustment indices of the retained factor would be acceptable.

\section{METHODS}

To achieve the purpose of the study, 250 high school athletes was selected. Out of which 124 were male and 126 were female athletes. Their ages ranged between 12 to 17 years. These athletes were selected on the basis of their active participation in games and sports and also have participated in various tournaments conducted by the different agencies and federation as well as the directorate of sports in the Assam region. To measure the self esteem level of the male and female athletes, the Self Esteem Questionnaire as devised by Rosenberg (1965) was used. It assessed the level of self esteem of an individual. The questionnaire consists of 10 items based on the four point rating scale.

\section{RESULTS}

To explore the study and lucid interpretation, Descriptive statistics such as mean and standard deviation were used. To establish the correlation matrix Pearson correlation was used. Further, to explore the perception of the high school athletes on their level of self esteem across all the ten items, factor analysis using principal component analysis extraction method and varimax rotation method were used. To see the gender based analysis $t$-test was used. Cronbach alpha was used to see the reliability of the retained items of the self esteem questionnaire.

It can be noticed after rotation the first $(26.769 \%)$, second $(10.738 \%)$, and third $(10.247 \%)$ explain a total variance of $(47.755 \%)$. The decision about the number of factors to be retained in the factor analysis is taken on the basis of eigenvalues. The only factor with eigenvalue more than 1 and items with a factor loading more than .50 were considered. If the factor has a low eigenvalues, then it is contributing little to the explanation of variances in the variable and may be dropped.

The scree plot proposed by Cattell (1966) is another popular technique. The scree plot is a plot against the 


\section{TABLE 1}

Total Variance Explained.

\begin{tabular}{|c|c|c|c|c|c|c|c|c|c|c|}
\hline \multirow{2}{*}{\multicolumn{2}{|c|}{ 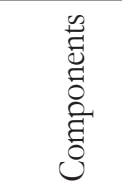 }} & \multicolumn{3}{|c|}{ Initial eigenvalues } & \multicolumn{3}{|c|}{$\begin{array}{l}\text { Extraction sums } \\
\text { of squared loading }\end{array}$} & \multicolumn{3}{|c|}{$\begin{array}{c}\text { Rotation sums } \\
\text { of squared loadings }\end{array}$} \\
\hline & & Total & $\begin{array}{c}\% \\
\text { variance }\end{array}$ & $\begin{array}{c}\text { Cumula. } \\
\%\end{array}$ & Total & $\begin{array}{c}\% \\
\text { variance }\end{array}$ & $\begin{array}{c}\text { Cumula. } \\
\%\end{array}$ & Total & $\begin{array}{c}\% \\
\text { variance }\end{array}$ & $\begin{array}{c}\text { Cumula. } \\
\%\end{array}$ \\
\hline Item & 1 & 2.677 & 26.769 & 26.769 & 2.677 & 26.769 & 26.769 & 2.137 & 21.374 & 21.374 \\
\hline Item & 2 & 1.074 & 10.738 & 37.507 & 1.074 & 10.738 & 37.507 & 1.454 & 14.544 & 35.918 \\
\hline Item & 3 & 1.025 & 10.247 & 47.755 & 1.025 & 10.247 & 47.755 & 1.184 & 11.837 & 47.755 \\
\hline Item & 4 & .927 & 9.272 & 57.026 & & & & & & \\
\hline Item & 5 & .877 & 8.768 & 65.795 & & & & & & \\
\hline Item & 6 & .863 & 8.626 & 74.421 & & & & & & \\
\hline Item & 7 & .705 & 7.048 & 81.469 & & & & & & \\
\hline Item & 8 & .689 & 6.891 & 88.360 & & & & & & \\
\hline Item & 9 & .600 & 5.998 & 94.358 & & & & & & \\
\hline Item 1 & & .564 & 5.642 & 100.000 & & & & & & \\
\hline
\end{tabular}

Legend: Item 1 - On the whole, I am satisfied with myself; Item 2 - At times, I think I am no good at all; Item 3 - I feel that I have a number of good qualities; Item 4 - I am able to do things as well as most other people; Item $\mathbf{5}$ - I feel I do not have much to be proud of; Item 6 - I certainly feel useless at times; Item 7 - I feel that I'm a person of worth, at least on an equal plane with others; Item 8 - I wish I could have more respect for myself; Item $\mathbf{9}$ - All in all, I am inclined to feel that I am a failure; Item 10 - I take a positive attitude toward myself.

\section{FIGURE 1}

A scree plot technique based on eigenvalues signifying a sharp drop in variance accounted for the factors merely represent error or unique components.

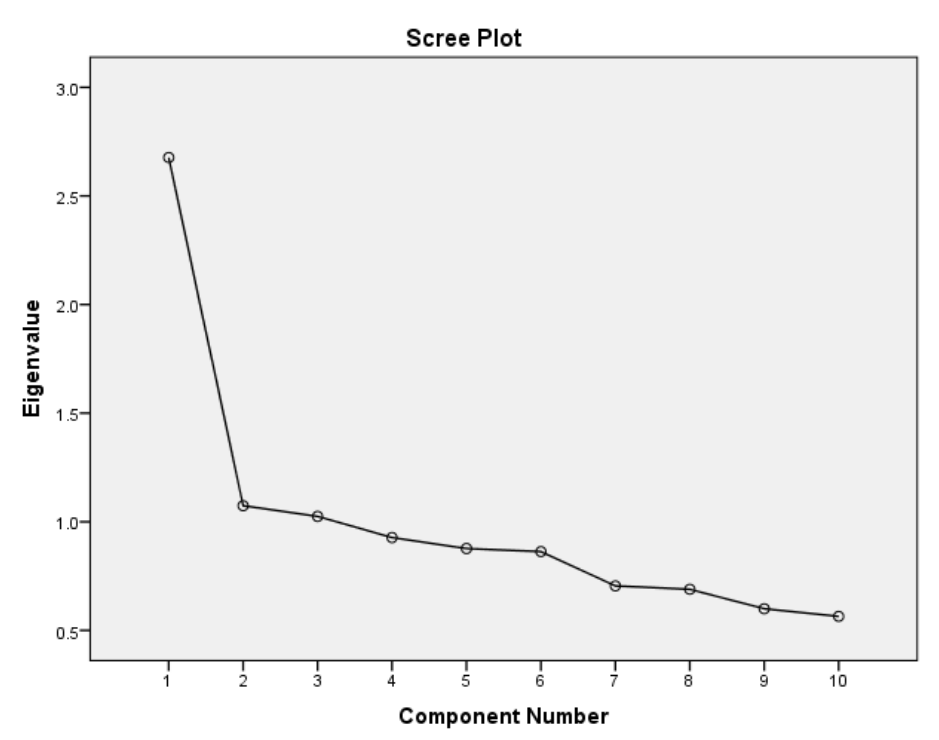

number of factors, and one looks for an "elbow" signifying a sharp drop in variance accounted for the factors merely represent error or unique components (Netemeyer, Bearden, \& Sharma, 2003) or we can say it is also based on a plot of the eigenvalues associated with successive factors (DeVelliss, 2003). Because each factor after the first is extracted from a matrix that is a residual of the previous factor's extraction, the amount of information in each successive factor is less than in its predecessors. Cattell suggested the 
right number of factors that can be determined by looking at the drop in the amount of information across successive factors. Inlay term, scree describes the rubble that collects on the ground following a landslide. This term, then implies that the vertical portion of the plot is where substantial factors are located while the horizontal portion is the scree, or rubble, that should be discarded. Ideally, the progression of factors will have a point at which the information drops off suddenly, with an abrupt transition from vertical to horizontal and a clear "elbow" (Ibid). The factors plotted along $\mathrm{X}$-axis against eigenvalues, on the Y-axis. As one moves toward the $\mathrm{X}$-axis (factors), the eigenvalues dropped. When the drop ceases and the curve made an elbow towards less steep de- cline. The purpose of factor extraction is merely to determine the appropriate number of factors to examine. Table 2 represent the results of factor analysis done on all the 10 items. We used the Statistical Package for Social Sciences (SPSS: version 20.00) to conduct an exploratory factor analysis Principal Component analysis and Varimax Rotation with Kaiser Normalization was done on the result obtained to the items of the factor on self esteem to assess the self esteem level of the athletes. It has been seen that none of the item was excluded from the analysis. When reporting the items for each of the factors, we only included items with factor coefficient loadings at or above .40. Although McDonald (1999) suggests that it is commonly accepted to consider an item as

TABLE 2

Rotated Component Matrix.

\begin{tabular}{|c|c|c|c|c|c|c|c|c|}
\hline \multirow{2}{*}{ Items } & \multirow{2}{*}{$M$} & \multirow{2}{*}{$S D$} & \multicolumn{4}{|c|}{ Component } & \multirow{2}{*}{$\dot{\alpha}$} & \multirow{2}{*}{$N$} \\
\hline & & & 1 & 2 & 3 & $h^{2}$ & & \\
\hline 2 & 2.28 & .623 & .712 & & & .552 & & 250 \\
\hline 3 & 2.29 & .700 & .451 & & & .356 & & 250 \\
\hline 5 & 2.24 & .693 & .696 & & & .495 & .633 & 250 \\
\hline 6 & 2.22 & .676 & .578 & & & .431 & & 250 \\
\hline 8 & 1.38 & .630 & .569 & & & .371 & & 250 \\
\hline 4 & 2.16 & .651 & & .558 & & .470 & & 250 \\
\hline 7 & 2.28 & .637 & & .422 & & .361 & .391 & 250 \\
\hline 9 & 2.32 & .589 & & .762 & & .594 & & 250 \\
\hline 1 & 2.40 & .581 & & & .434 & .396 & & 250 \\
\hline 10 & $2-30$ & .555 & & & .864 & .750 & .265 & 250 \\
\hline
\end{tabular}

Legend: $\mathbf{M}$ - Mean; SD - Standard deviation; $\mathbf{N}$ - Number of respondents; Item 1 - On the whole, I am satisfied with myself; Item 2 - At times, I think I am no good at all; Item 3 - I feel that I have a number of good qualities; Item 4 - I am able to do things as well as most other people; Item 5 - I feel I do not have much to be proud of; Item 6 - I certainly feel useless at times; Item 7 - I feel that I'm a person of worth, at least on an equal plane with others; Item 8 - I wish I could have more respect for myself; Item 9 - All in all, I am inclined to feel that I am a failure; Item 10 - I take a positive attitude toward myself.

salient if its factor loading is at least .30, we adopted a more rigorous standard based upon Hair, Anderson, Tatham, and Black's (1995) suggestion that in a sample size of 200 using loadings of at least .40 will provide more statistical power (power $=.80$ ) than a loading of at least .30 (power $<.80$ ). Also, in an attempt to identify simple structures (Thurstone, 1947), we excluded items that met the .40 cutoff on more than one factor. Rotation converged in 5 iterations. It is noticed that 7 items were above the loading of .50 .
It is also noticed that after EFA three items showed low in factor loading $(<.50)$. Description of the items were, "I feel that I have a number of good qualities", "I feel that I'm a person of worth, at least on an equal plane with others", and "On the whole, I am satisfied with myself". The result of Kaiser-Meyer-Olkin Measure of Sampling Adequacy (KMO) test which tells whether the sample size taken for the factor analysis was adequate or not. It tests whether the partial correlation among the variables are small. KMO values range from 0 to 1 . The closer the value to 1 
the more adequate is the sample to run the factor analysis. Usually KMO more than .5 is considered is sufficient for doing factor analysis reliably. For this present study, Kaiser-Meyer-Olkin Measure of Sampling Adequacy yielded a measure of .781 which is $>.5$; hence the sample size is adequate to run the analysis and to make it more lucid. Further the Bartlett's Test of Sphericity was used to test the null hypothesis the correlation matrix is the identity matrix. Since the significance value $(p<.01)$ of Bartlett's Test is .00 , which is $<.01$ hence it is significant and the correlation matrix is not an identity matrix. Thus, it may conclude the factor model is appropriate. The Communalities of all the variables shows its appropriateness because the values of all the items after varimax rotation are more than $<.4$ except the item 3 (Sharma, 2007).

The study was further having gone through a gender based analysis on the perception of self esteem among all the high school athletes with all the 10 items of self esteem. To see the gender based analysis t-test (11.93) was administered at the .05 level of significance. The result of t-test found a significant difference between the two groups. It is also noticeable for the table that the level of self esteem of male high school athletes is higher than the female high school athletes.

Further a Confirmatory factor analysis was administered with all the retained items irrespective of any factor loading to see the validity of the original version and which provided the graphical representation of the pattern of correlations between a set of variables. Accordingly, the result of the model fit summary supported the indices (Measurement Models Fit Indices Examined) extended by Leach et al. (2008). Confirmatory Factor analysis was tested where the Model Fit Summary are: $\chi^{2}=36.928$ with $\mathrm{df}=32$ to be significant as CFI $=.978$, RMSEA $=.025$, GFI $=$ $.972, \mathrm{AGFI}=.952, \mathrm{PGFI}=.566, \mathrm{PCLOSE}=.905$.

TABLE 3

Gender based difference of self esteem.

\begin{tabular}{lccccccc}
\hline Gender & $N$ & $d f$ & $M$ & $M D$ & $S D_{M}$ & $S E_{D}$ & $t$ \\
\hline Male & 124 & 1.85 & 24.87 & \multirow{2}{*}{3.91} & .166 & .32845 & \multirow{2}{*}{11.93} \\
Female & 126 & 3.15 & 20.96 & & .281 & .32717 & \\
\hline
\end{tabular}

Legend: $\mathbf{N}$ - Number of respondents; df - Degrees of freedom; M - Mean; SD - Standard deviation; $\mathbf{M D}$ - Mean difference; $\mathbf{S D}_{\mathbf{M}}$ - Stadrad error mean; $\mathbf{S E}_{\mathbf{D}}$ - Stadrad error difference; $\mathbf{t}$ - T-test.

\section{DISCUSSION}

The overarching aim of the study was to find the perception of self esteem among the high school students and also to see the difference of self-esteem between both sexes. Out of ten items; 7 items showed higher level of factor loadings, but the remaining three items didn't show higher item loading, but still these three items were included in the further analysis because factor coefficient loadings at or above .40 is considerably relevant (McDonald, 1999). The description of the items are, "I feel that I have a number of good qualities", "I feel that I'm a person of worth, at least on an equal plane with others", and "On the whole, I am satisfied with myself". Level of self esteem between male and female was found significantly different as it was hypothesized. This same result is also corroborated by the finding of Tiggemann and Williamson (2000). So from this finding we could assume that male student's physical activities would be more emphasized than the female students and the same result is also corroborated by the finding of that participation in extracurricular activities has been linked to: higher self-esteem (Duda, 1989; Holland \& Andre, 1994; Jaffee \& Ricker, 1993), lower dropout rates (Finn, 1993), better attendance (O’Brien \& Rollefson 1995), success in school and on tests (Snyder \& Spreitzer, 1990; Soltz, 1986), reduction of at-risk behaviors (Eccles \& Barber, 1999; Ebie 1998); physical fitness (Rainey, MeKeown, Sargent, \& Valois, 1998); and as a predictor of success in college and later in life (O’Brien \& Rollefson, 1995). Spence and Poon (1997) reported that $79 \%$ of males in their survey chose sports because they believed they were capable of being good athletes and good at sports, while $68 \%$ of female athletes reportedly playing for socialization reasons, and physical fitness. Freyer (1997) investigated the reasons for participation in team sports of adolescent females. She found that her sample of 130 adolescent female athletes identified 11 variables of sports participation. These included increasing athletic skills, achievements in compe- 


\section{FIGURE 2}

Represents three factors Measurement model extracted from the total items of Self esteem.

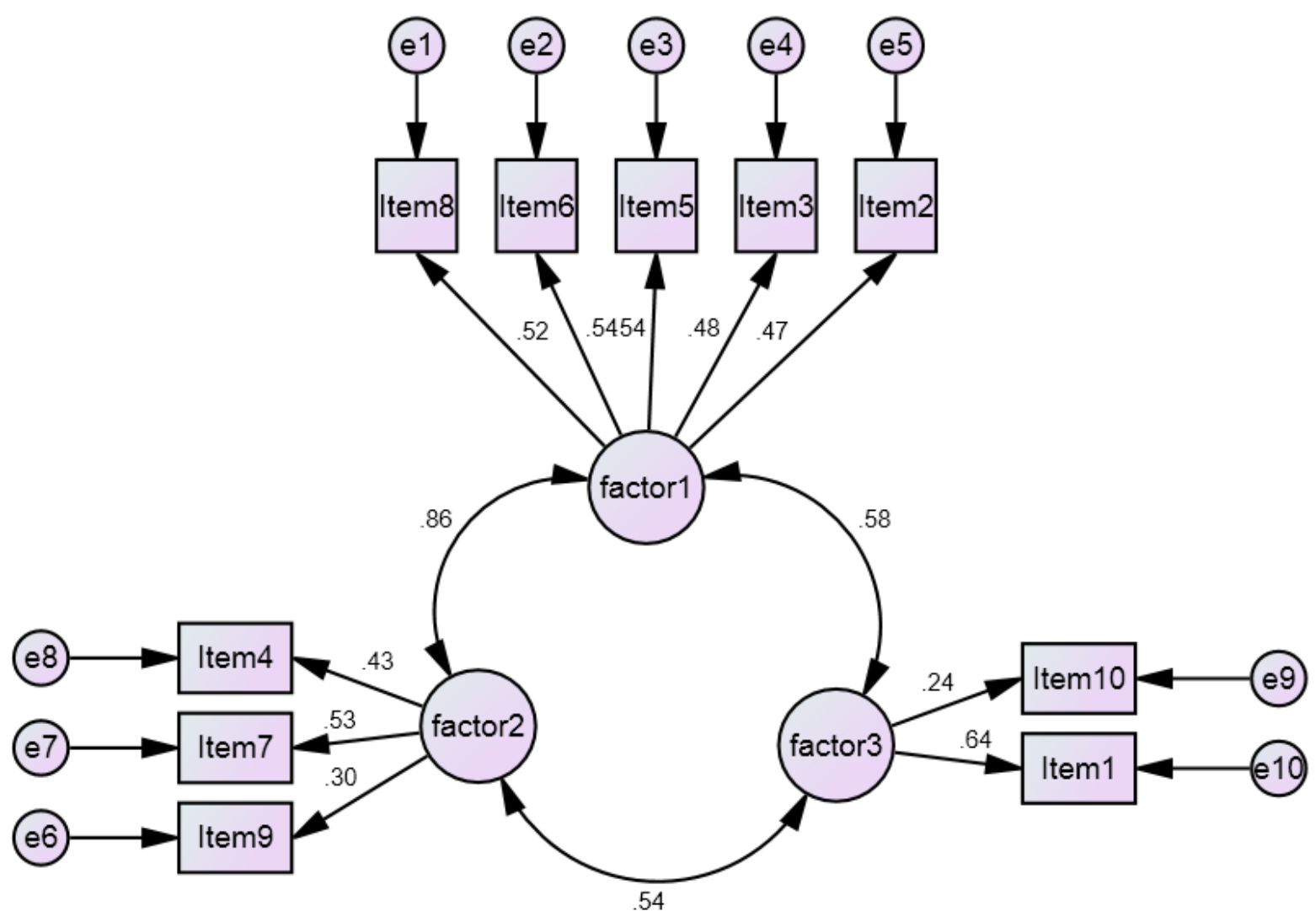

tition, staying physically fit and attractive, improving feelings of self-worth, and making new friends. These results are supported by Dworkin, Larson, and Hansen, (2003) who emphasized that extracurricular activities are different from many other school activities because of the opportunities provided to develop socially and leadership skills, increase peer-awareness, and improve emotional fitness. The results were further enhanced with CFA where the result of the Confirmatory factor analysis Model Fit Summary indicated: $\chi^{2}=36.928$ with $\mathrm{df}=32$ to be significant as $\mathrm{CFI}=.978$, RMSEA $=.025$, GFI $=.972$, AGFI $=.952$, PGFI $=.566$, PCLOSE $=.905$. which supports the indices as per the Measurement Models Fit Indices supported (Leach et al., 2008). Hence it is assumed that the items were perfect to measure the level of self esteem on the aforesaid samples as it also corroborates with the global results conducted by various researchers.

\section{CONCLUSION}

Within the limitations of the study and on the basis of statistical finding, so the following conclusions are drawn. It was found that all the items were retained after applying an exploratory factor analysis of self-esteem as it was hypothesized earlier. Confirmatory analysis was also found a significant model fit summary indicated which supports the indices as per the Measurement Models Fit Indices supported by Leach et al. (2008). Further, it was found that there was a significant difference in the mean score of the male and female self-esteem level; where male students showed a higher mean level. From this finding we can assume that, female students are not taking active participation in games and sports and leisure activities (Vealey, 1992; Wilkins et al., 1988; Yeng \& Hemsley, 1996). As much as the same initiative been taken up by the male high school students (Tiggemann and Williamson, 2000).

\section{REFERENCES}

Bosscher, R. J. (1993). Running and mixed physical exercises with depressed psychiatric patients. International Journal of Sport Psychology, 24(2), 170-184.

Cattell, R. B. (1966). The scree test for the number of factors. Multivariate Behavioral Research, 1, 245-276. 
Delaney, W., \& Lee, C. (1995). Self-esteem and sex roles among male and female high school students: Their relationship to physical activity. Australian Psychologist, 30(2), 84-87. doi: 10.1080/00050069508258908

DeVellis, R. F. (2003). Scale development: Theory and applications. 2nd ed. Thousand Oaks, CA: Sage Publications

Duda, J. L. (1989). Relationship between task and ego orientation and the perceived purpose of sport among high school athletes. Journal of Sport and Exercise Psychology, 11(3), 318-335.

Dworkin, J. B., Larson, R., \& Hansen, D. (2003). Adolescents' accounts of growth experiences in youth activities. Journal of Youth and Adolescence, 52(1), 17-26. doi: 10.1023/A:1021076222321

Eccles, J. S., Barber, B. L., Stone, M., \& Hunt, J. (2003). Extracurricular activities and adolescent development. Journal of Social Issues, 59(4), 865-889. doi: 10.1046/j.0022-4537.2003. 00095.x

Finkenberg, M. E. (1990). Effect of participation in taekwondo on college women's self-concept. Perceptual and Motor Skills, 71(3), 891-894. doi: 10.2466/pms.1990.71.3.891

Finn, J. (1989). Withdrawing from school. Review of Educational Research, 59(2), 117-142. doi: 10.3102/00346543059002117

Ford, H. T. Jr., Puckett, J. R., Reeve, T. G., \& Lafavi, R. G. (1991). Effects of selected physical activities on global self-concept and bodycathexis scores. Psychological Reports, 68(3), 1339-1443. doi: 10.2466/pr0.1991.68.3c.1339; doi: 10.2466/PR0.68.4.1339-1343

Freyer, K. W. (1997). The impact of team sports on the adolescent female. Unpublished Dissertation. Dissertation Abstracts International Section A: Humanities \& Social Sciences 57 (7-A) p. 2854.

Hair, J., Anderson, R., Tatham, R., \& Black, W. (1995). Multivariate data analysis with readings. 4th ed. Upper Saddle, NJ: Prentice-Hall.

Hardy, C., \& Crace, K. (2009). Dealing with precompetitive anxiety. Sport Psychology Training Bulletin, 3513-3517. doi: 10.1080/ 10615809608249393

Holland, A., \& Andre, T. (1994). The relationship of self-esteem to selected personal and environmental resources of adolescents. Adolescence, 29(114), 345-360. PMid: 8085486

Jaffee, L., \& Ricker, S. (1993). Physical activity and self-esteem in girls: the teen years. Melpomene Journal, 12(3), 19-26.

Kalliopuska, M. (1987). Relation of empathy and self-esteem to active participation in Finnish baseball. Perceptual and Motor Skills, 65, 107-113. doi: 10.2466/pms.1987.65.1.107

Leach, C., van Zomeren, M., Zebel, S., Vliek, M., Pennekamp, S., Doosje, B., ... Spears, R. (2008). Self-definition and self-investment: A multi component model of in-group identification. Journal of Personality and Social Psychology, 95, 144165.

Marsh, H. W. (1986). Global self-esteem: its relation to specific facets of self-concept and their importance. Journal of Personality and Social Psychology, 51(6), 1224-1236. doi: 10.1037/00223514.51.6.1224

Marsh, H. W. (1995). A Jamesian model of selfinvestment and self-esteem: comment on Pelham. Journal of Personality and Social Psychology, 69(6), 1151-1160. doi: 10.1037/0022-

3514.69.6.1151

Marsh, H. W., Hey, J., Roche, L. A., \& Perry, C. (1997). Structure of physical self-concept: elite athletes and physical education students. Journal of Educational Psychology, 89(2), 369-380. doi: 10.1037/0022-0663.89.2.369

McDonald, R. P. (1999). Test theory: A unified treatment. Mahwah, NJ: Lawrence Erlbaum Associates.

McDonald, R. P., \& Marsh, H. W. (1990). Choosing a multivariate model: no centrality and goodness of fit. Psychological Bulletin, 107, 247-255. doi: 10.1037/0033-2909.107.2.247

McNeal, R. B. Jr. (1995). Extracurricular activities and high school dropouts. Sociology of Education, 68(1), 62-81. doi: 10.2307/2112764

Mead, G. H. (1934). Mind, self, and society. Chicago, IL: University of Chicago Press.

Melnick, M. J., \& Mookerjee, S. (1991). Effects of advanced weight training on body-cathexis and self-esteem. Perceptual and Motor Skills, 72(3), 1335-1345. doi: 10.2466/pms.1991.72.3c.1335. doi: $10.2466 /$ pms.1991.72.3c.1335

Netemeyer, R. G., Bearden, W. O., \& Sharma, S. (2003). Scaling procedure issue and application.

Thousand Oaks. CA.: Saga. PMid: 12880188

Nunnally, J. (1978). Psychometric theory. 2nd ed. New York, NY: McGraw-Hill.

O’Brien, E., \& Rollefson, M. (1995). Extracurricular participation and student engagement. Education Policy Issues: Statistical Perspectives. Retrieved from http://www.askeric.org

Pascarella, E. T., \& Smart, J. C. (1991). Impact of intercollegiate athletic participation for African American and Caucasian men: Some further evidence. Journal of College Student Development, 32(2), 123-130. 
Rosenberg, M. (1965). Society and the adolescent selfimage. Princeton, NJ: Princeton University Press.

Rosenberg, M. (1979). Conceiving the self. New York, NY: Basic Books.

Sharma, S. (2007). Ethical foundations of new corporate model: Implications for strategy and leadership'. In A. Ghosh and G. Banerjee (Eds.), Proceedings of 10th International Annual Convention on Strategic Management for Firms in Developing Countries (pp. 242-245). New Delhi, India: Allied Publishers Pvt Ltd.

Spence, J. C., \& Poon, P. (1997). Research Update: Results from the Alberta Schools Athletic Association Survey. Retrieved from http:/ / www.cdc.gov/ healthyyouth/health_and_academics/pdf/ health-academic-achievement.pdf.

Steinberg, L. (1996). Beyond the classroom: Why school reform has failed and what parents need to do. New York, NY: Simon \& Schuster.

Thurstone, L. L. (1947). Multiple factor analysis. Chicago, IL: University of Chicago Press.

Tiggemann, M., \& Williamson, S. (2000). The effect of exercise on body satisfaction and self-esteem as a function of gender and age. Sex Roles, 43(12), 119-127. doi: 10.1023/A:1007095830095
Tucker, L. R., \& Lewis, C. (1973). A reliability coefficient for maximum likelihood factor analysis. Psychometric, 38(1), 1-10. doi: 10.1007/ BF02291170

Vealey, R. S. (1992). Personality and sport: A comprehensive view. In T. S. Horn (Ed.), Advances in sport psychology (pp. 25-60). Champaign, IL: Human Kinetics Publishers.

Velikić, D., Knežević, J., \& Rodić, N. (2014). Relations of some personality traits and characteristics of sportsmen with the level of sports anxiety. SportLogia, 10(1), 35-43. doi: 10.5550/sgia.141001.en.005V

Wilkins, J. A., Boland, F. J., \& Albinson, J. (1988). A comparison of male and female university athletes and nonathletes on eating disorder indices: Are athletes protected? Journal of Sport Behavior, 14, 129-143.

Yeung, R. R., \& Hemsley, D. R. (1997). Personality, exercise and psychological well-being: Static relationships in the community. Personality and Individual Differences, 22(1), 47-53. doi: 10.1016/0191-8869(95)00222-7

Received: October 12, 2014 Revision received: December 18, 2014 Accepted: December 25, 2014

Correspondence to: Dilsad Ahmed, PhD FVill: Debosthan Bazar; District: Nagaon; Assam, India. Pin: 782481 Phone: 00918473803483 E-mail: dilshadstrings@yahoo.co.in 